\title{
Durabilidade de madeira de eucalipto citriodora (Corymbia citriodora (Hook.) K.D. Hill \& L.A.S. Johnson) tratada com CCA em ambiente amazônico
}

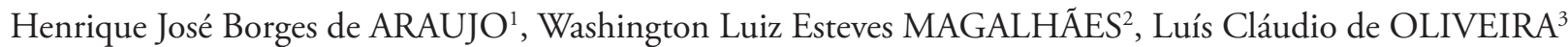

\begin{abstract}
RESUMO
A intensa exploração econômica tem causado diminuição do estoque original das espécies madeireiras amazônicas, incluindo aquelas de alta durabilidade natural destinadas a usos em contato com o solo. A escassez dessas madeiras resulta na elevação do preço, inviabilizando economicamente seu uso, sendo uma alternativa a substituiçáo por espécies plantadas de rápido crescimento tratadas com preservativos. Outra vantagem, além da econômica, de utilizar espécies plantadas em substituição às tradicionais é ambiental, pois reduzirá a pressão exploratória sobre aquelas. Este estudo teve por objetivo avaliar o grau de degradação biológica de madeira de eucalipto citriodora (Corymbia citriodora (Hook.) K.D. Hill \& L.A.S. Johnson) tratado por processo a vácuo e pressão com arseniato de cobre cromatado (CCA) e exposta em ensaio de campo em Rio Branco-AC. O ensaio foi implantado em maio de 2005 com estacas tratadas ou náo com CCA. As variáveis avaliadas foram: 1) degradaçáo por fungos, 2) degradação por cupins, e 3) região ou parte da peça afetada. A partir da terceira avaliação (47 meses de ensaio), $100 \%$ dos corpos de prova não tratados foram classificados com o grau de degradação máximo e, ao contrário, $100 \%$ dos tratados com CCA, decorridos 60 meses de ensaio, foram classificados com o grau mínimo. As partes não tratadas com maior e menor grau de degradação foram, respectivamente, o topo inferior e a parte aérea acima de $10 \mathrm{~cm}$ do solo. A degradação provocada por fungos foi levemente inferior à dos cupins. O ensaio aponta para a viabilidade técnica do uso de madeira tratada de eucalipto em substituição às espécies tradicionais da Amazônia.
\end{abstract}

PALAVRAS-CHAVE: Preservação de madeira, processo a vácuo e pressão, espécies madeireiras amazônicas.

\section{Durability of eucalyptus citriodora wood (Corymbia citriodora (Hook.) K.D. Hill \& L.A.S. Johnson) treated with CCA in the Amazon environment}

\begin{abstract}
The intense economic exploration has caused a decrease of the original stock of Amazon woody species, including those of high natural durability used in soil contact. The lack of those species results in increased price that makes economically unfeasible of the use, an alternative is the replacement by planted species of fast-growing treated with preservatives. Another advantage of to use species planted to replace the traditional species is environmental, because this will reduce the exploratory pressure on these species. The objective of this study is to evaluate the degree of biological degradation of eucalyptus citriodora wood (Corymbia citriodora (Hook.) K.D. Hill \& L.A.S. Johnson) treated with chromated copper arsenate (CCA) under vacuum and pressure process and exposed in field experiment in Rio Branco-AC. The experiment was implemented in May 2005 with cuttings treated with CCA and not treated. The variables evaluated were: 1) degradation by fungi, 2) degradation by termites, and 3) region or part of the piece affected. After the 3rd evaluation ( 47 months of test), 100\% of the specimens without treated were classified with the maximum degree of degradation and, in contrast, $100 \%$ of the specimens treated with CCA, after 60 months of test, were classified with the minimum degree of degradation. The parties of the pieces without treatment with the higher and the lesser degrees of degradation were, respectively, the inferior head and the aerial part above $10 \mathrm{~cm}$ of soil. The degradation caused by fungi was slightly lower than that of termites. The field experiment has shown that is technically feasible the use of eucalyptus wood to replace the traditional species of the Amazon.
\end{abstract}

KEYWORDS: Wood preservation, vacuum and pressure process, Amazon timber species.

\footnotetext{
1 Pesquisador da Embrapa Acre. BR 364, km 14, Caixa Postal 321, CEP 69908-970, Rio Branco-AC, Brasil. Tel.: (068) 3212-3200. E-mail: henrique@cpafac.embrapa.br

2 Pesquisador da Embrapa Florestas. Estrada da Ribeira, km 111, Caixa Postal 319, CEP 83411-000, Colombo-PR, Brasil. Tel.: (041) 3675-5600.

E-mail:wmagalha@cnpf.embrapa.br

3 Pesquisador da Embrapa Acre. E-mail: Iclaudio@cpafac.embrapa.br
} 


\section{INTRODUÇÃO}

A utilização econômica aliada às ações antrópicas de desmatamento, com destaque para atividades pecuárias, especialmente devido ao fluxo migratório iniciado nos anos 70 e 80 tem promovido forte pressão exploratória sobre algumas espécies florestais madeireiras amazônicas, resultando em uma diminuição do estoque original desses recursos.

Hoje, a maior parte das espécies madeireiras amazônicas consideradas tradicionais e mais conhecidas no mercado consumidor, devido à intensa exploração nos últimos anos, tem sua ocorrência natural bastante reduzida e está em crescente processo de escassez e, em alguns casos, até mesmo sob ameaça de extinção.

Entre as espécies amazônicas em processo de escassez constam madeiras destinadas as mais variadas aplicaçôes, desde as mais requintadas (móveis de luxo, artigos decorativos, torneados, instrumentos musicais etc.), passando pelas mais correntes (construção civil, peças estruturais, assoalhos, esquadrias etc.) até as aplicaçôes rústicas, com destaque ao meio rural (mourôes, estacas, pontes, postes etc.), principalmente em usos em que a madeira fica em contato com o solo, ambiente que favorece alto grau de degradação. Tais aplicaçôes são, na maioria dos casos, baseadas no conhecimento, às vezes secular, do homem no uso dessas madeiras.

São exemplos de espécies de madeiras amazônicas tradicionalmente utilizadas em contato com o solo: maçaranduba (Manilkara surinamensis (Miq.) Dubard); itaúba (Mezilaurus itauba (Meisn.) Taub. ex Mez.); aroeira (Astronium lecointei Ducke); acariquara (Minquartia guianensis Aubl.) e piqui (Caryocar villosum (Aubl.) Pers.). Essas espécies possuem alta durabilidade natural e são capazes de resistir, por muitos anos, em boas condiçôes de uso em ambientes muito adversos.

Durabilidade natural de uma madeira é definida como a vida média útil em serviço quando exposta a fatores abióticos (temperatura, umidade, luminosidade, acidez etc.) e a organismos xilófagos, principalmente fungos e insetos (Lepage et al. 1986; Santini 1988; Jankowsky 1990; Jesus et al. 1998).

Obedecendo a lei da oferta e da procura, a escassez das madeiras nativas de alta durabilidade natural nas florestas de produção resulta na elevação do valor comercial no mercado consumidor. No presente, por exemplo, o preço de mourōes e estacas de madeiras nativas está em níveis muito altos, o que tem inviabilizado economicamente seu uso. Diante disso, a substituição dessas espécies por espécies plantadas de rápido crescimento, como o eucalipto (Eucalyptus spp. ou Corymbia spp.), devidamente tratadas com preservativos químicos, apresenta-se como uma excelente alternativa para o problema.

Atualmente, no Acre, o preço de estacas tratadas de eucalipto para cercados é bastante competitivo com o preço de estacas das espécies nativas tradicionalmente utilizadas em contato com o solo, mesmo considerando os custos do tratamento preservativo e do transporte do centro-sul do país, pois não há no Estado plantios dessa espécie e tampouco unidades industriais (usinas) de preservação. Outro aspecto vantajoso para se utilizar espécies plantadas e tratadas em substituição às tradicionais é de ordem ambiental, uma vez que haverá redução da pressão exploratória sobre as espécies nativas, o que é muito positivo do ponto de vista de conservação e recomposição dos estoques naturais.

Em meio aos métodos de preservação de madeira utilizados no mundo, os mais eficientes são aqueles aplicados sob condiçôes de vácuo e pressão, e dentre estes o mais importante é o de "célula cheia", também conhecido por processo Bethell, que tem por objetivo preencher ao máximo as células da madeira com o produto preservativo (CTFT 1970; Cockcroft 1971; Déon 1978).

A preservação pelo processo Bethell é efetuada em autoclaves horizontais de grande porte (podendo passar de 100 mil litros) e consiste basicamente nas seguintes etapas: 1) carga da madeira; 2$)$ aplicação de vácuo inicial $(600 \mathrm{mmHg})$ por aproximadamente quarenta e cinco minutos; 3) injeção da solução preservativa; 4) liberação do vácuo e aplicação de pressão $\left(12,2 \mathrm{kgf} \mathrm{cm}^{-2}\right)$ por aproximadamente três horas; 5$)$ liberação da pressão e aplicação de vácuo final $(400 \mathrm{mmHg})$ por aproximadamente quarenta e cinco minutos; e 6) descarga da madeira (Lepage et al. 1986; Sales-Campos et al. 2003).

Um dos principais produtos utilizados no tratamento preservativo da madeira é o arseniato de cobre cromatado, conhecido como CCA, preservativo hidrossolúvel a base de cobre $(\mathrm{Cu})$, cromo (Cr) e arsênio (As) (Moreschi 1985; Velizarova et al. 2004; Galvão et al. 2004). Considerando que não há um preservativo para madeira perfeitamente seguro para o homem e altamente efetivo contra a deterioração biológica, o CCA, desenvolvido na Índia na década de 30, é o preservativo que apresenta os melhores resultados quanto a eficiência, segurança e a relação benefício/custo (Geisse 2006). A impregnação da madeira com CCA deve ser feita exclusivamente por processos preservativos a vácuo e pressão e de célula cheia.

Apesar de o CCA ser um preservativo amplamente aceito no mundo inteiro, existe a restrição da toxidez ao homem, devido ao elemento arsênio, e da baixa eficiência para madeiras de pouca permeabilidade (Richardson 1993; Ramos et al. 2006), que é o caso de muitas espécies nativas amazônicas potencialmente preserváveis para usos em contato com o solo, mas que são dotadas de alta densidade e baixa porosidade e permeabilidade (Burger e Richter 1991; Araujo 2002). Numa tentativa de resolver o problema da toxidez do arsênio presente no CCA, desenvolveu-se na Alemanha, no início dos anos 60, o preservativo CCB, que substitui o arsênio pelo boro (B) na composição, no entanto, este produto apresenta como 
desvantagens maior lixiviação e menor eficiência à proteção contra insetos (Moreschi 1985).

Madeiras de eucalipto tratadas com CCA a serem utilizadas em contato com o solo (postes, estacas e mouróes) tem garantia de durabilidade, oferecida pelas empresas de preservaçáo em autoclaves, de 15 anos (Olx 2011), enquanto que as indústrias químicas fabricantes dos produtos preservativos, a exemplo da Montana Química S.A., sediada em São Paulo-SP, fabricante do produto Osmose $\mathrm{K} 33 \mathrm{C}$, indicam que essa durabilidade que pode alcançar de 20 a 30 anos em serviço (Montana 2011).

A durabilidade da madeira preservada é influenciada pela qualidade do preservativo, pelo processo utilizado para o tratamento, pelas características anatômicas da madeira, pela presença de substâncias recalcitrantes na madeira (como a lignina) e pelas condiçóes ambientais as quais a peça tratada está exposta (Gjovik e Baechler 1977; Galvão e Jankowsky 1986; Aprile et al. 1999).

A decomposição da madeira depende de uma série de fatores bióticos e abióticos, entre os quais as suas características físicas e químicas, à concentração dos extrativos tóxicos presentes no lenho, à comunidade decompositora e às condiçóes climáticas, com destaque para a temperatura e a umidade (Swift et al. 1979; Paes 2002). A durabilidade natural das espécies de rápido crescimento, como por exemplo a Corymbia citriodora (Hook.) K.D. Hill \& L.A.S. Johnson (antigo Eucalyptus citriodora Hook.), em geral, é menor do que nas de crescimento lento (Scheffer 1973; Panshin e Zeeuw 1980), o que é relacionado à redução no teor de extrativos na madeira devido à rápida taxa de crescimento (Hillis 1984).

A região amazônica é detentora da maior biodiversidade do planeta, com estreita ligaçáo a um conjunto de habitats igualmente diversos, onde se encontram cerca de $50 \%$ de todas as espécies existentes (Val e Almeida-Val 2004; WWF 2010). A comunidade decompositora xilófaga é também muito diversa (Jesus et al. 1998). Além disso, o ambiente tropical amazônico apresenta altas temperatura e umidade, além de médias destas variáveis pouco oscilantes no decorrer do ano, portanto, ótimas para o desenvolvimento dos organismos xilófagos, especialmente os fungos apodrecedores e os cupins de solo.

O presente estudo objetivou avaliar o grau de degradação por organismos xilófagos, fungos e cupins, de estacas de eucalipto citriodora (C. citriodora.) náo tratadas e tratadas a vácuo e pressão com preservativo CCA e expostas há sessenta meses em ensaio de campo na área experimental da Embrapa (Empresa Brasileira de Pesquisa Agropecuária) Acre, em Rio Branco, estado do Acre.

\section{MATERIAL E MÉTODOS}

O ensaio de durabilidade de madeira (Figura 1) foi implantado no campo experimental da Embrapa Acre, município de Rio Branco, estado do Acre (S1001’30,7” e W067042'23,6"). Nesta área, de acordo com Brasil (1976), o clima é do tipo Aw (Köppen), com três meses de seca, precipitação pluvial anual entre 1.800 a $2.000 \mathrm{~mm}$ e temperatura média anual de $24^{\circ} \mathrm{C}$; o solo é distrófico, com alto teor de argila e boa drenagem; a topografia é plana; a incidência de luz solar é plena, sem sombreamento; a vegetaçáo existente é basicamente constituída por gramíneas, sendo a cobertura original a floresta tropical úmida amazônica.

O ensaio foi composto por 30 corpos de prova (estacas roliças) de eucalipto (C. citriodora), sem casca, procedentes e tratadas em Cianorte-PR, com medidas de $1,10 \mathrm{~m}$ de comprimento e diâmetro médio de $7,0 \mathrm{~cm}$, sendo metade $(15$ estacas) tratada com CCA e a outra metade sem tratamento preservativo. As estacas foram fincadas no solo até a metade do comprimento $(0,55 \mathrm{~m})$ e dispostas em delineamento inteiramente casualizado em seis linhas com cinco unidades cada, com espaçamento de 3,0 m entre as linhas e 1,0 m dentro das linhas.

$\mathrm{O}$ produto utilizado no tratamento das estacas foi o Osmose K33C, fabricado pela Montana Química S.A., pelo método "célula cheia" (processo Bethell), por processo a vácuo e pressão, com aplicação de vácuo inicial $(555 \mathrm{mmHg})$ por quarenta minutos, pressão $\left(23,0 \mathrm{kgf} \mathrm{cm}^{-2}\right)$ por duas horas e vácuo final $(400 \mathrm{mmHg})$ por 10 minutos. A retenção do ingrediente ativo foi de $6,5 \mathrm{~kg} \mathrm{~m}^{3}$.

Desde a implantação do ensaio, em maio de 2005, foram efetuadas quatro avaliaçóes, correspondendo a intervalos médios de 15 meses, a saber: primeira avaliação, em outubro de 2006; segunda avaliação, em novembro de 2007; terceira avaliação, em maio de 2009; e quarta avaliação, em maio de 2010. O intervalo entre a primeira e a última avaliação totalizou sessenta meses (cinco anos).

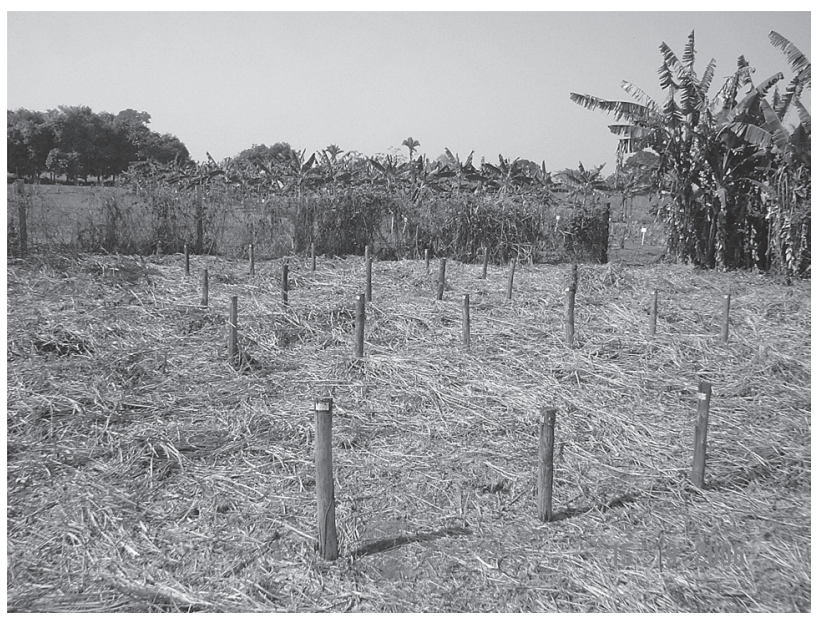

Figura 1 - Vista do ensaio de durabilidade de estacas de eucalipto localizado no campo experimental da Embrapa Acre, Rio Branco-AC. 
As estacas foram avaliadas quanto à ação de organismos xilófagos considerando as seguintes variáveis: 1) degradação por fungos; 2) degradação por cupins; e 3) região ou parte da peça afetada. A avaliação de diferentes regióes da estaca em separado objetivou verificar, de modo comparativo, os diferentes graus de degradação que há entre estas regióes, dado que se expóem a condiçôes ambientais e níveis de degradaçấo desiguais.

A degradação das estacas foi avaliada quanto: a) ao estado geral - considerou-se o grau de degradaçáo da peça como um todo; b) a parte em contato com o solo - região da estaca compreendida entre $10 \mathrm{~cm}$ acima e $10 \mathrm{~cm}$ abaixo do nível do solo; c) a parte aérea - regiáo da estaca acima de $10 \mathrm{~cm}$ do nível do solo; d) a parte subterrânea - regiáo da estaca abaixo de $10 \mathrm{~cm}$ do nível do solo; e) o topo superior - face transversal superior (área) da estaca e f) o topo inferior - face transversal inferior (subterrânea) da estaca (Figura 2).

A avaliação do ensaio de campo consistiu em uma inspeção visual da cada corpo de prova retirando-o do solo e atribuindo, distintamente para a infestação de fungos e cupins e para as suas diferentes partes (Figura 2), uma nota conforme classificação do grau de degradação biológica apresentada na Tabela 1, a qual é baseada no método da International Union of Forest Research Organizations (IUFRO), descrito por Lepage (1970).

Considerando estacas tratadas ou náo com $\mathrm{CCA}$ e as variáveis do ensaio (degradaçáo por fungos e cupins e partes do

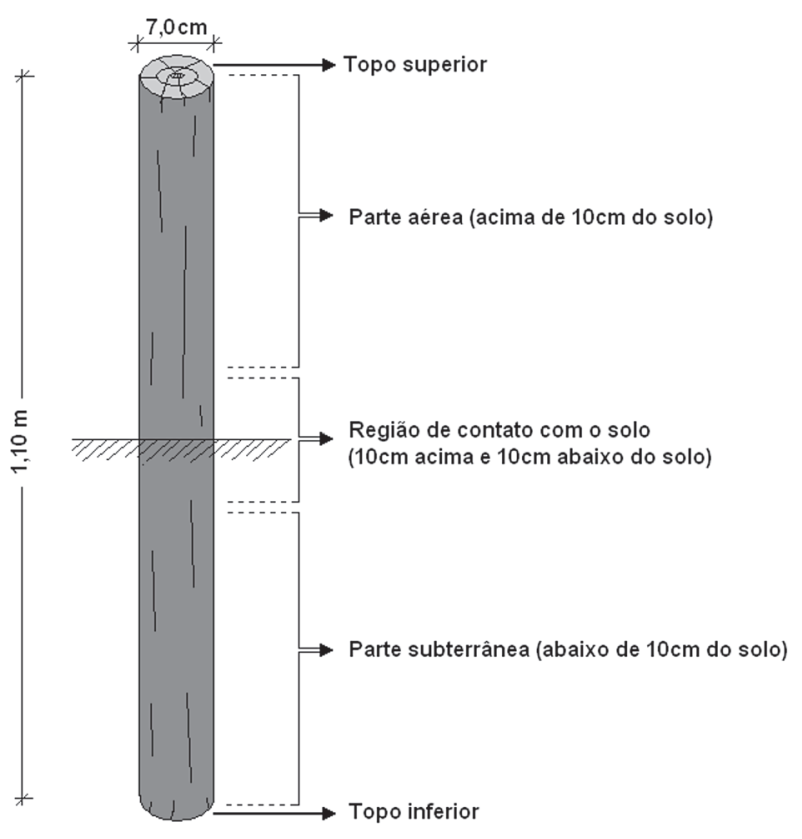

Figura 2 - Partes avaliadas das estacas de madeira quanto à degradação por organismos xilófagos.
Tabela 1 - Classificação do grau de degradação dos corpos de prova (estacas) por organismos xilófagos.

\begin{tabular}{cc}
\hline NOTA ATRIBUIDA & CLASSIFICAÇÃO \\
\hline 10 & Sadio \\
9 & Levemente atacado \\
7 & Moderadamente atacado \\
4 & Intensamente atacado \\
0 & Destruído ou rompido \\
\hline
\end{tabular}

Fonte: International Union of Forest Research Organizations (IUFRO), citado por Lepage (1970).

corpo de prova) e as próprias avaliações, com a totalização das notas atribuídas pode-se verificar quais as situaçôes em que as estacas foram mais resistentes e em quais foram mais suscetíveis à degradaçâo biológica, sendo as de maior durabilidade as que mais pontuaram e vice-versa.

\section{RESULTADOS E DISCUSSÃO}

Devido a baixa densidade e durabilidade natural (Costa et al. 1997; Shimizu e Carvalho 2000; Paes 2002), as estacas de eucalipto sem tratamento preservativo foram rapidamente infestadas e degradadas por fungos e cupins, enquanto que as estacas tratadas com preservativo CCA permaneceram sadias, sem sinais de ataque destes organismos.

Com o intuito de exemplificar o grau de degradaçáo em relaçáo ao tempo de exposiçáo dos corpos de prova no ensaio de campo, são mostradas, na Figura 3, uma estaca tratada (a) após 60 meses (quarta avaliação), uma estaca não tratada (b) após 16 meses (primeira avaliação) e outra estaca não tratada (c) após 30 meses de exposição (segunda avaliação).

Nos exemplos (Figura 3) observa-se a estaca tratada (a) completamente isenta de qualquer dano causado por organismos xilófagos, enquanto que as estacas não tratadas (b) e (c) apresentam-se intensamente atacadas, mesmo expostas a períodos de tempo, respectivamente para (b) e (c), quatro e duas vezes menores do que o da estaca tratada. Nas estacas atacadas é bastante visível a infestação por fungos com seus corpos de frutificação (conhecidos popularmente por "orelhade-pau") e de galerias de cupins do tipo subterrâneo. No caso da estaca (c), uma das poucas remanescentes não tratadas ainda ereta na segunda avaliação, percebe-se uma condição em que há total colapso e fragmentação estrutural do lenho da madeira ocasionado pelo ataque de fungos e cupins.

Segundo Lepage et al. (1986), a presença de fungos do tipo "orelha-de-pau" (classe basidiomicetos), indica que a madeira está em estágio avançado de degradação, e que já sofreu infestação por fungos de podridão mole (ascomicetos e deuteromicetos) e adentrou no clímax da sucessão dos fungos apresentando podridôes dos tipos parda e branca, em que há a decomposição das paredes celulares e da lignina. 

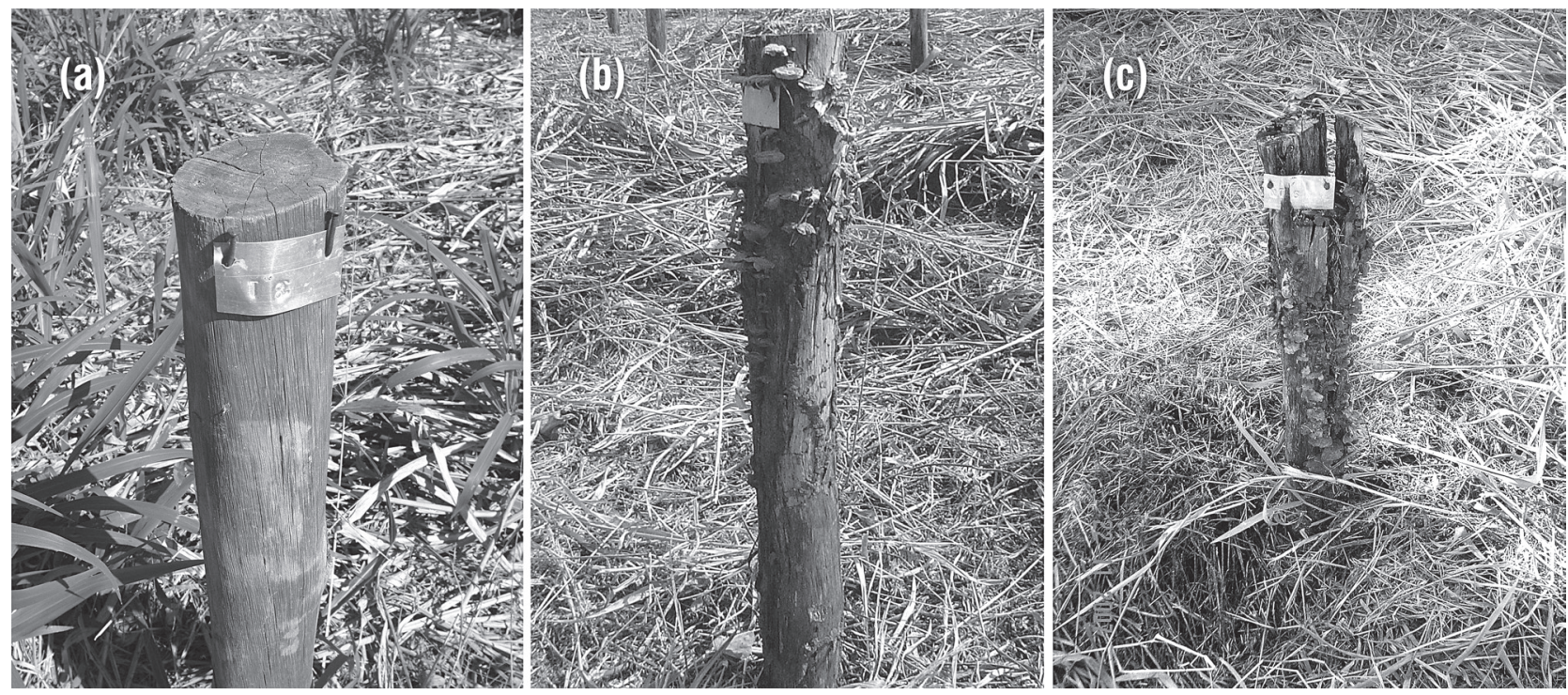

Figura 3 - Estacas de eucalipto do ensaio de durabilidade no campo experimental da Embrapa Acre: (a) tratada com CCA, após 60 meses de implantação; (b) não tratada, após 16 meses de implantação; (c) não tratada, após 30 meses de implantação.

Neste estudo não foram realizadas identificaçôes dos organismos xilófagos ocorrentes, no entanto, consta na literatura que em ambiente amazônico a diversidade destes é elevada, diferente de outras regiōes brasileiras. De acordo com Jesus et al. (1998), em um estudo de durabilidade de madeiras nativas realizado na região de Manaus-AM, foram identificadas na área do experimento um total 42 espécies de fungos, 19 espécies de cupins e nove espécies de briófitas. Mill (1982), investigando a fauna de cupins no baixo Rio Negro, próximo a Manaus-AM, registrou a presença de 43 espécies em florestas de terra firme, 34 espécies em capoeiras e 12 espécies em áreas inundáveis de igapó. Em florestas de terra firme no Estado do Pará, Bandeira e Macambira (1988) encontraram 88 espécies de cupins e Macambira (1997) encontrou 68 espécies. Embora não podendo generalizar, Trevizan et al. (2008) avaliando a degradação natural em ambiente de Mata Atlântica de toras de cinco espécies, entre elas uma espécie de eucalipto, em Seropédica-RJ, registraram a presença de apenas três espécies de cupins e duas de coleobrocas e Cavalcante e Lelis (1974), em um campo de apodrecimento de madeira de eucalipto em Mogi Guaçu-SP, identificaram seis espécies de fungos.

Os resultados do monitoramento da durabilidade efetuado para o total das estacas tratadas com CCA e náo tratadas, por grau de degradação, por tipo de organismo xilófago (cupim e fungo) e para as diferentes partes da peça avaliadas, são apresentados na Tabela 2.

Tabela 2 - Distribuição das estacas de eucalipto tratadas com CCA e não tratadas por partes avaliadas, por classificação do grau de degradação e por tipo de organismo xilófago.

\begin{tabular}{|c|c|c|c|c|c|c|c|c|c|c|}
\hline \multirow{2}{*}{ PARTE } & \multirow{2}{*}{ TRAT } & \multirow{2}{*}{ CLASS } & \multicolumn{2}{|c|}{$1^{\mathrm{a}}$ AVALIAÇÃO } & \multicolumn{2}{|c|}{$2^{\mathrm{a}}$ AVALIAÇÃO } & \multicolumn{2}{|c|}{$3^{\text {a }}$ AVALIAÇÃO } & \multicolumn{2}{|c|}{$4^{\mathrm{a}}$ AVALIAÇÃO } \\
\hline & & & CUPIM & FUNGO & CUPIM & FUNGO & CUPIM & FUNGO & CUPIM & FUNGO \\
\hline \multirow{10}{*}{ 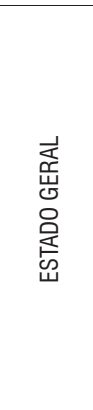 } & \multirow{5}{*}{$\begin{array}{l}\text { 志 } \\
\underset{\mathbf{c}}{\mathbb{1}} \\
\mathbb{E}\end{array}$} & 10 & $15(100 \%)$ & $15(100 \%)$ & $15(100 \%)$ & $15(100 \%)$ & $15(100 \%)$ & $15(100 \%)$ & $15(100 \%)$ & $15(100 \%)$ \\
\hline & & 9 & - & - & - & - & - & - & - & - \\
\hline & & 7 & - & - & - & - & - & - & - & - \\
\hline & & 4 & - & - & - & - & - & - & - & - \\
\hline & & 0 & - & - & - & - & - & - & - & - \\
\hline & \multirow{5}{*}{ 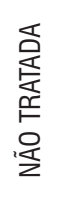 } & 10 & - & - & - & - & - & - & - & - \\
\hline & & 9 & - & $1(7 \%)$ & - & - & - & - & - & - \\
\hline & & 7 & - & $1(7 \%)$ & - & $1(7 \%)$ & - & - & - & - \\
\hline & & 4 & $9(60 \%)$ & $7(47 \%)$ & $7(47 \%)$ & $7(47 \%)$ & - & - & - & - \\
\hline & & 0 & $6(40 \%)$ & $6(40 \%)$ & $8(53 \%)$ & $7(47 \%)$ & $15(100 \%)$ & $15(100 \%)$ & $15(100 \%)$ & $15(100 \%)$ \\
\hline
\end{tabular}




\begin{tabular}{|c|c|c|c|c|c|c|c|c|c|c|}
\hline \multirow{2}{*}{ PARTE } & \multirow{2}{*}{ TRAT } & \multirow{2}{*}{ CLASS } & \multicolumn{2}{|c|}{$1^{\text {a }}$ AVALIAÇÃO } & \multicolumn{2}{|c|}{$2^{\mathrm{a}}$ AVALIAÇÃO } & \multicolumn{2}{|c|}{$3^{\text {a }}$ AVALIAÇÃO } & \multicolumn{2}{|c|}{$4^{\mathrm{a}}$ AVALIAÇÃ̃ } \\
\hline & & & CUPIM & FUNGO & CUPIM & FUNGO & CUPIM & FUNGO & CUPIM & FUNGO \\
\hline \multirow{10}{*}{ 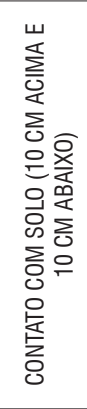 } & \multirow{5}{*}{$\begin{array}{l}\text { 吉 } \\
\text { 产 } \\
\text { 品 }\end{array}$} & 10 & $15(100 \%)$ & 15 (100\%) & $15(100 \%)$ & 15 (100\%) & 15 (100\%) & 15 (100\%) & 15 (100\%) & $15(100 \%)$ \\
\hline & & 9 & - & - & - & - & - & - & - & - \\
\hline & & 7 & - & - & - & - & - & - & - & - \\
\hline & & 4 & - & - & - & - & - & - & - & - \\
\hline & & 0 & - & - & - & - & - & - & - & - \\
\hline & \multirow{5}{*}{ 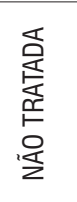 } & 10 & - & - & - & - & - & - & - & - \\
\hline & & 9 & - & - & - & - & - & - & - & - \\
\hline & & 7 & $1(7 \%)$ & $1(7 \%)$ & - & - & - & - & - & - \\
\hline & & 4 & 10 (67\%) & $10(67 \%)$ & $9(60 \%)$ & 8 (53\%) & - & - & - & - \\
\hline & & 0 & $4(27 \%)$ & $4(27 \%)$ & $6(40 \%)$ & 7 (47\%) & 15 (100\%) & $15(100 \%)$ & $15(100 \%)$ & $15(100 \%)$ \\
\hline \multirow{10}{*}{ 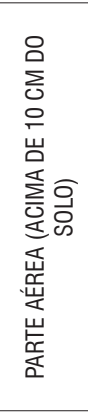 } & \multirow{5}{*}{ 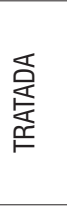 } & 10 & $15(100 \%)$ & $15(100 \%)$ & $15(100 \%)$ & $15(100 \%)$ & $15(100 \%)$ & $15(100 \%)$ & $15(100 \%)$ & $15(100 \%)$ \\
\hline & & 9 & - & - & - & - & - & - & - & - \\
\hline & & 7 & - & - & - & - & - & - & - & - \\
\hline & & 4 & - & - & - & - & - & - & - & - \\
\hline & & 0 & - & - & - & - & - & - & - & - \\
\hline & \multirow{5}{*}{ 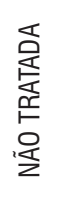 } & 10 & - & - & - & - & - & - & - & - \\
\hline & & 9 & - & - & - & - & - & - & - & - \\
\hline & & 7 & $3(20 \%)$ & 11 (73\%) & $1(7 \%)$ & $9(60 \%)$ & - & - & - & - \\
\hline & & 4 & 11 (73\%) & $3(20 \%)$ & 10 (67\%) & $4(27 \%)$ & - & - & - & - \\
\hline & & 0 & $1(7 \%)$ & $1(7 \%)$ & $4(27 \%)$ & $2(13 \%)$ & 15 (100\%) & $15(100 \%)$ & $15(100 \%)$ & $15(100 \%)$ \\
\hline \multirow{10}{*}{ 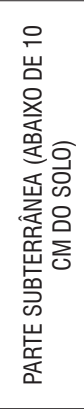 } & \multirow{5}{*}{ 哀 } & 10 & $15(100 \%)$ & $15(100 \%)$ & $15(100 \%)$ & $15(100 \%)$ & $15(100 \%)$ & $15(100 \%)$ & 15 (100\%) & $15(100 \%)$ \\
\hline & & 9 & - & - & - & - & - & - & - & - \\
\hline & & 7 & - & - & - & - & - & - & - & - \\
\hline & & 4 & - & - & - & - & - & - & - & - \\
\hline & & 0 & - & - & - & - & - & - & - & - \\
\hline & \multirow{5}{*}{$\begin{array}{l}\text { 喜 } \\
\text { 委 } \\
\text { 点 } \\
\text { 足 }\end{array}$} & 10 & - & - & - & - & - & - & - & - \\
\hline & & 9 & - & - & - & - & - & - & - & - \\
\hline & & 7 & - & - & - & - & - & - & - & - \\
\hline & & 4 & 10 (67\%) & $10(67 \%)$ & $8(53 \%)$ & $7(47 \%)$ & - & - & - & - \\
\hline & & 0 & $5(33 \%)$ & $5(33 \%)$ & $7(47 \%)$ & $8(53 \%)$ & 15 (100\%) & $15(100 \%)$ & $15(100 \%)$ & $15(100 \%)$ \\
\hline \multirow{10}{*}{ 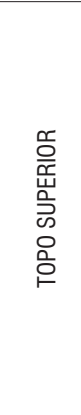 } & \multirow{5}{*}{$\begin{array}{l}\text { 喜 } \\
\text { 委 } \\
\text { 点 }\end{array}$} & 10 & 15 (100\%) & 15 (100\%) & 15 (100\%) & 15 (100\%) & 15 (100\%) & 15 (100\%) & 15 (100\%) & $15(100 \%)$ \\
\hline & & 9 & - & - & - & - & - & - & - & - \\
\hline & & 7 & - & - & - & - & - & - & - & - \\
\hline & & 4 & - & - & - & - & - & - & - & - \\
\hline & & 0 & - & - & - & - & - & - & - & - \\
\hline & & 10 & - & - & - & - & - & - & - & - \\
\hline & 尽 & 9 & - & - & - & - & - & - & - & - \\
\hline & @ & 7 & $3(20 \%)$ & $4(27 \%)$ & $1(7 \%)$ & $2(13 \%)$ & - & - & - & - \\
\hline & 운 & 4 & $6(40 \%)$ & $5(33 \%)$ & $6(40 \%)$ & $5(33 \%)$ & - & - & - & - \\
\hline & & 0 & $6(40 \%)$ & $6(40 \%)$ & $8(53 \%)$ & $8(53 \%)$ & $15(100 \%)$ & $15(100 \%)$ & $15(100 \%)$ & $15(100 \%)$ \\
\hline & & 10 & $15(100 \%)$ & 15 (100\%) & 15 (100\%) & $15(100 \%)$ & 15 (100\%) & 15 (100\%) & $15(100 \%)$ & $15(100 \%)$ \\
\hline & & 9 & - & - & - & - & - & - & - & - \\
\hline & 昰 & 7 & - & - & - & - & - & - & - & - \\
\hline & $\stackrel{⿰ 口 口}{\models}$ & 4 & - & - & - & - & - & - & - & - \\
\hline 觅 & & 0 & - & - & - & - & - & - & - & - \\
\hline 0 & & 10 & - & - & - & - & - & - & - & - \\
\hline ᄒे & 足 & 9 & - & - & - & - & - & - & - & - \\
\hline & 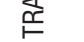 & 7 & - & - & - & - & - & - & - & - \\
\hline & 0 & 4 & $6(40 \%)$ & $6(40 \%)$ & $3(20 \%)$ & $4(27 \%)$ & - & - & - & - \\
\hline & & 0 & $9(60 \%)$ & $9(60 \%)$ & $12(80 \%)$ & $11(73 \%)$ & 15 (100\%) & 15 (100\%) & $15(100 \%)$ & $15(100 \%)$ \\
\hline
\end{tabular}

Em que: TRAT = tratamento com CCA (arseniato de cobre cromatado) e sem tratamento; CLASS = classificação do grau de degradação. 
A partir da terceira avaliação, ocorrida 47 meses (três anos e 11 meses) após a implantação do ensaio, para quaisquer das regióes ou partes avaliadas, $100 \%$ os corpos de prova não tratados foram classificados com o grau de degradação máximo, ou seja, destruídos ou rompidos, e praticamente desapareceram do ensaio, restando somente fragmentos. Ao contrário, todos os corpos de prova tratados com CCA, decorridos 60 meses da implantação do ensaio, permaneceram livres de ataque, sendo classificados com o grau de degradaçấo mínimo, ou seja, sadios.

A soma (totalização) das notas atribuídas pelo método de avaliaçáo da IUFRO permitiu estabelecer um ranking das partes das estacas quanto ao grau de degradaçáo (Tabela 3).

As partes não tratadas que apresentaram o maior e o menor grau de degradação (maior e menor somatório das notas atribuídas) por cupins e fungos, nas quatro avaliaçóes efetuadas foram, respectivamente, o topo inferior, com o total de 76 pontos, e a parte aérea acima de $10 \mathrm{~cm}$ do solo, com o total de 280 pontos. Portanto, o topo inferior é a parte da estaca menos resistente e mais suscetível à degradação, enquanto que a parte aérea acima de $10 \mathrm{~cm}$ do solo é a mais resistente e menos suscetível à degradação por cupins e fungos.

As demais partes das estacas (Contato com solo $-10 \mathrm{~cm}$ acima e $10 \mathrm{~cm}$ abaixo, 162 pontos; Parte subterrânea - abaixo de $10 \mathrm{~cm}$ do solo, 140 pontos; Topo superior, 158 pontos) náo tratadas apresentaram um grau de degradaçáo similar ao estado geral da estaca, que reflete a média de degradação das partes e cuja pontuaçáo total foi de 143 pontos. Todas as estacas tratadas com CCA obtiveram pontuação máxima nas quatro avaliaçóes (1200 pontos).

Embora tenha pouca relevância do ponto de vista da durabilidade das estacas não tratadas, dado que a totalidade degradou-se muito rapidamente (após 16 meses a maioria absoluta estava deteriorada e sem serventia), a informaçáo de quais partes degradaram com mais intensidade pode ser útil, por exemplo, no caso da aplicaçáo de produtos preservativos convencionais (como pincelamento com carbolineum) em que se recomenda mais atenção para aquelas partes mais susceptíveis ao ataque biológico.

Em relação ao grau de degradação provocado por cupins e fungos, observou-se que os danos provocados pelos fungos são um tanto menores que os provocados pelos cupins nas condiçôes do ensaio em questáo (total de 257 e 292 pontos e de 186 e 224 pontos, respectivamente para cupins e fungos na primeira e na segunda avaliaçôes).

\section{CONCLUSÕES}

Após sessenta meses do ensaio de campo observam-se resultados promissores em relação à durabilidade da madeira de eucalipto citriodora tratada com CCA, apontando para a viabilidade técnica da sua utilização em substituição às espécies tradicionais nativas da Amazônia. No entanto, e para

Tabela 3 - Totalização dos pontos (escala da IUFRO) das estacas de eucalipto tratadas com CCA e não tratadas nas avaliações efetuadas por partes avaliadas e por organismo xilófago.

\begin{tabular}{|c|c|c|c|c|c|c|c|c|c|c|}
\hline \multirow{2}{*}{ PARTE AVALIADA } & \multirow{2}{*}{ TRAT } & \multicolumn{2}{|c|}{$1^{\text {a }}$ AVALIAÇÃO } & \multicolumn{2}{|c|}{$2^{\mathrm{a}}$ AVALIAÇÃO } & \multicolumn{2}{|c|}{$3^{\text {a AVALIAÇÃO }}$} & \multicolumn{2}{|c|}{$4^{\mathrm{a}}$ AVALIAÇÃO } & \multirow{2}{*}{ TOTAL } \\
\hline & & CUPIM & FUNGO & CUPIM & FUNGO & CUPIM & FUNGO & CUPIM & FUNGO & \\
\hline \multirow{2}{*}{ Estado geral } & Tratada & 150 & 150 & 150 & 150 & 150 & 150 & 150 & 150 & 1200 \\
\hline & Não Tratada & 36 & 44 & 28 & 35 & 0 & 0 & 0 & 0 & 143 \\
\hline \multirow{2}{*}{$\begin{array}{l}\text { Contato com solo }(10 \mathrm{~cm} \\
\text { acima e } 10 \mathrm{~cm} \text { abaixo) }\end{array}$} & Tratada & 150 & 150 & 150 & 150 & 150 & 150 & 150 & 150 & 1200 \\
\hline & Não Tratada & 47 & 47 & 36 & 32 & 0 & 0 & 0 & 0 & 162 \\
\hline \multirow{2}{*}{$\begin{array}{l}\text { Parte aérea (acima de } 10 \\
\text { cm do solo) }\end{array}$} & Tratada & 150 & 150 & 150 & 150 & 150 & 150 & 150 & 150 & 1200 \\
\hline & Não Tratada & 65 & 89 & 47 & 79 & 0 & 0 & 0 & 0 & 280 \\
\hline \multirow{2}{*}{$\begin{array}{l}\text { Parte subterrânea (abaixo } \\
\text { de } 10 \mathrm{~cm} \text { do solo) }\end{array}$} & Tratada & 150 & 150 & 150 & 150 & 150 & 150 & 150 & 150 & 1200 \\
\hline & Não Tratada & 40 & 40 & 32 & 28 & 0 & 0 & 0 & 0 & 140 \\
\hline \multirow{2}{*}{ Topo superior } & Tratada & 150 & 150 & 150 & 150 & 150 & 150 & 150 & 150 & 1200 \\
\hline & Não Tratada & 45 & 48 & 31 & 34 & 0 & 0 & 0 & 0 & 158 \\
\hline \multirow{2}{*}{ Topo inferior } & Tratada & 150 & 150 & 150 & 150 & 150 & 150 & 150 & 150 & 1200 \\
\hline & Não Tratada & 24 & 24 & 12 & 16 & 0 & 0 & 0 & 0 & 76 \\
\hline \multirow{2}{*}{ TOTAL } & Tratada & 900 & 900 & 900 & 900 & 900 & 900 & 900 & 900 & - \\
\hline & Não Tratada & 257 & 292 & 186 & 224 & 0 & 0 & 0 & 0 & - \\
\hline
\end{tabular}

Em que: TRAT $=$ tratamento com CCA (arseniato de cobre cromatado) e sem tratamento. 
fins de complementaçáo, este estudo necessita ainda, além de continuar o monitoramento do ensaio, de estudos relativos à viabilidade econômica, ocorrência dos organismos xilófagos e a questóes ambientais, especialmente referentes à lixiviação do preservativo ao solo.

\section{BIBLIOGRAFIA CITADA}

Aprile, F.M.; Delitti, W.B.C.; Bianchini JR., L. 1999. Aspectos cinéticos da degradaçáo de laminados de madeira em ambientes aquático e terrestre. Revista Brasileira de Biologia. 59 (3): 485-492.

Araujo, H.J.B. 2002. Agrupamento das espécies madeireiras ocorrentes em pequenas áreas sob manejo florestal do Projeto de Colonizaçáo Pedro Peixoto (AC) por similaridade das propriedades físicas e mecânicas. Piracicaba, 168p. Tese (Mestrado). Escola Superior de Agricultura "Luiz de Queiroz", Universidade de São Paulo.

Bandeira, A.G.; Macambira, M.L.J. 1988. Térmitas de Carajás, Estado do Pará, Brasil - composição faunística, distribuição e hábito alimentar. Bol. Museu Paraense Emilio Goeldi, 4 (2):175190.

Brasil. 1976. Ministério das Minas e Energia. Departamento de Produção Mineral. Projeto Radambrasil. Folha SC19. Levantamento dos Recursos Naturais. Vol. 12. Rio Branco. Rio de Janeiro, RJ. 458 pp.

Burger, L.M.; Richter, H.G. 1991. Anatomia da madeira. São Paulo: Nobel, 154 pp.

Cavalcante, M.S.; Lelis, A.T. 1974. Organismos xilófagos coletados nos campos de apodrecimento instalados pelo convênio IPTIF em diversas regióes do estado de São Paulo. Preservação de Madeira, 5 (1): 29-50.

Cockcroft, R. 1971. Timbers preservatives and methods of treatment. Timberlab Papers Princes Risborough Laboratory, 46: 1-6.

Costa, M.M.; Colodette, J.L.; Gomide, J.L.; Foelkel, C.E.B. 1997. Avaliação preliminar do potencial de quatro madeiras de eucalipto na produção de polpa solúvel branqueada pela seqüência OA(ZQ)P. Árvore, Viçosa-MG, 21: 385-392.

CTFT. 1970. Note sur l'injection des bois en autoclave. Centre Technique Forestier Tropical, Division de Préservation. NogentSur-Marne, France: CTFT. 7 pp.

Déon, G. 1978. Manuel de préservation des bois en climat tropicauxe. Centre Technique Forestier Tropical, Division de Préservation. Nogent-Sur-Marne, France: CTFT. 111 pp.

Galvão, A.P.M.; Magalhães, W.L.E.; Mattos, P.P. 2004. Processos práticos para preservar madeira. Colombo: Embrapa Florestas, CNPF, (Embrapa Florestas. Documentos, 96). 49 pp.

Galvão, A.P.M.; Jankowsky, I.P. 1986. Durabilidade da madeira de Eucalyptus urophylla S. T. Blake preservada por processos sem pressão - avaliaçáo de ensaios de campo. Scientia Forestalis, 33: 59-64.

Geisse, M.E. 2006. Tratamento de madeira de reflorestamento em autoclave. Revista da Madeira, 100: 96-99.
Gjovik, L.R.; Baechler, R.H. 1977. Selection, production, procurement and of preservative treated wood. Madison, Forest Products Laboratory. 37 p.

Hillis, W.E. 1984. Wood quality and utilization. In: Hillis, W.E.; Brown, A.G. (Eds.). Eucalypts for wood production. Sydney: CSIRO/Academic Press, 159-289.

Jankowsky, I.P. 1990. Fundamentos de preservação de madeiras. Piracicaba: ESALQ/USP. p 1-12, (Documentos Florestais, 11).

Jesus, M.A.; Morais, J.W.; Abreu, R.L.S; Cardias, M.F.C. 1998. Durabilidade natural de 46 espécies de madeiras amazônicas em contato com o solo em ambiente florestal. Scienta Forestalis, 54: 81-91.

Lepage, E.S. 1970. Método padrão sugerido pela IUFRO para ensaios de campo com estacas de madeira. Preservação de madeiras, 1 : 205-216.

Lepage, E.S.; Oliveira, A.M.F.; Lelis, A.T.; Lopez, G.A.C.; Chimelo, J.P.; Oliveira, L.C.S.; Cañedo, M.D.; Cavalcante, M.S.; Ielo, P.K.Y.; Zanotto, P.A.; Milano, S. 1986. Manual de preservação de madeiras. São Paulo: IPT. 2. ed., 708 pp.

Macambira, M.L.J. 1997. Os cupins (Insecta:Isoptera). In: Lisboa, P.L.B. (Org). Caxiuanã. Museu Paraense Emílio Goeldi, pp 347-354.

Mill, A.E. 1982. Populaçôes de térmitas (Insecta, Isoptera) em quatro habitats no baixo Rio Negro. Acta Amazonica. 12: 53-60.

Montana. 2011. (http://www.montana.com.br/Guia-da-Madeira/ Industrializacao/ Madeira-Serrada/Construção). Acesso: 29/03/2011.

Moreschi, J.C. 1985. Ensaios biológicos: uma nova alternativa para a determinaçáo dos ingredientes ativos do preservativo CCA e estudos de interações. Dissertação de Mestrado, Universidade Federal do Paraná, Curitiba, Paraná. 128 pp.

Olx, 2011. (http://sorocaba.olx.com.br/eucalipto-tratadoautoclavado-com-15-anos-de-garantia-iid-80233702). Acesso: 29/03/2011.

Paes, J.B. 2002. Resistência natural da madeira de Corymbia maculata (Hook.) K.D.Hill \& L.A.S. Johnson a fungos e cupins xilófagos, em condiçôes de laboratório. Árvore, Viçosa-MG, 26 (6): 761-767.

Panshin, A.J.; Zeeuw, C. 1980. Textbook of wood technology. 4.ed. New York: Mc Graw Hill, 722 pp.

Ramos, I.E.C.; Paes, J.B; Farias Sobrinho, D.W.; Santos, G.J.C. 2006. Eficiência do CCB na resistência da madeira de algaroba (Prosopis juliflora (Sw.) D.C.) em ensaio de apodrecimento acelerado. Árvore, Viçosa-MG, 30(5): 811-820.

Richardson, B.A. 1993. Wood preservation. 2. ed. London: E \& FN Spon, 226p.

Sales-Campos, C.; Vianez, B.F.; Mendonça, M.S. 2003. Estudo da variabilidade da retenção do preservante CCA tipo A na madeira de Brosimum rubescens Taub. Moraceae - (pau-rainha) uma espécie madeireira da região amazônica. Árvore, Viçosa-MG, 21(6): 845-853. 
Santini, E.J. 1988. Biodeterioração e preservação da madeira. Santa Maria: CEPEF/FATEC, 125 pp.

Scheffer, T. C. 1973. Microbiological degradation and its casual organisms. In: Nicholas, D. D. (Ed.). Wood deterioration and its prevention treatments: degradation and protection of wood. Syracuse: Syracuse University, 2: 31-106.

Shimizu, J.Y.; Carvalho, P.E..R. 2000. Primeira aproximação na indicação de eucaliptos para produção de madeira na região de Quaraí, RS. Boletim de Pesquisa Florestal. 40: 101-110.

Swift, M.J.; Heal, D.W.; Anderson, J.M. 1979. Studies in ecologydecomposition in terrestrial and aquatic ecosystems. Oxford: Blackwell. p.54-94.
Trevisan, H.; Marques, F.M.T.; A.G. 2008. Degradação natural de toras de cinco espécies florestais em dois ambientes. Floresta, Curitiba, 38(1): 33-41.

Val, A.L.; Almeida-Val, V.M.F. 2004. Rio Amazonas: tesouro descoberto. Ciência e Cultura (SBPC). 56: 9-10.

Velizarova, E., Ribeiro, A.B., Mateus, E.P., Ottosen, L.O. 2004. Effect of different extracting solutions on electrodialytic remediation of CCA-treated wood waste. Part 1. Behaviour of $\mathrm{Cu}$ and Cr. Journal of Hazardous Materials, 107(3): 103-113.

WWF. 2010. Amazon alive! A decade of discovery 1999-2009. World Wildlife Fund: WWF, Brasilia-DF, 57 p.

Recebido em 30/11/2010

Aceito em 15/05/2011 
